\title{
Çimentolu Macun Dolgu Yönteminin Uygulanmasında Bazı Katkı Malzemelerinin Puzolanik Özelliklerinin Araştırılması
}

\author{
Investigation of Pozzolanic Properties of Some Additive Materials in Cemented Paste \\ Backfill
}

\author{
Ataç BAŞÇETİN ${ }^{1, \mathrm{~b}}$, Hasan EKER ${ }^{* 2, \mathrm{a}}$, Deniz ADIGÜZEL ${ }^{1, \mathrm{c}}$, Serkan TÜYLÜ ${ }^{1, \mathrm{~d}}$ \\ ${ }^{1}$ İstanbul Üniversitesi - Cerrahpaşa, Mühendislik Fakültesi, Maden Mühendisliği Bölümü, 34320, İstanbul \\ ${ }^{2}$ Gümü̈şhane Üniversitesi, Mühendislik ve Doğa Bilimleri Fakültesi, Maden Mühendisliği Bölümü, 29100, Gümüşhane
}

• Geliş tarihi / Received: 30.09.2019 • • Düzeltilerek geliş tarihi / Received in revised form: 20.02.2020 • Kabul tarihi / Accepted: 28.02.2020

$\ddot{O} \mathbf{z}$

Son zamanlarda geliştirilen ve yaygın bir şekilde kullanılan çimentolu macun dolgu (ÇMD) yöntemi; maden atıklarının bertarafı konusunda sektöre hem işletme hem çevresel, hem de yasal mevzuatın uygulanması açısından birçok faydalar sağlamaktadır. Bu yüzden; ülkemizdeki bazı maden işletmelerinde son yıllarda çimentolu macun dolgu (ÇMD) yöntemi tercih edilmeye başlanmıştır. Bu yöntemin en büyük maliyet kalemlerinden biri bağlayıcı giderleridir. Bu çalışmada; ÇMD'da kullanılan Portland çimento (PÇ) yerine zeolit (Z), yüksek firın cürufu (YFC), uçucu kül (UK) ve silis dumanı (SD) gibi puzolanik katkı malzemelerinin kullanılabilirliği incelenmiştir. Bu çalışmada referans (R, sadece çimento içeren) ve Z, YFC, UK ve SD katkılı ÇMD karışımlarının 28 ve 90 gün kür süreleri sonunda tek eksenli basınç dayanımları ve eğilme dayanımları incelenmiş ve elde edilen tek eksenli basınç ve eğilme dayanımları değerleri kullanılarak puzolanik aktivite indeksi değerleri belirlenmiştir. Atık, çimento (ağırlıkça \% 11) ve su ile oluşturulan referans numuneleri ve çimentonun yerine (\% 11) \% 25 oranında YFC, \% 20 Z, \% 10 UK, \% 5 SD ikameli ÇMD numunelerinin 28 ve 90 günlük kür süreleri sonunda tek eksenli basınç dayanımı (TEBD) deneyleri gerçekleştirilmiştir. Elde Edilen sonuçlara göre; 28 ve 90 gündeki en yüksek basınç ve eğilme dayanımları UK numunelerinde elde edilmiştir. Puzolanik aktivite indeksinin en yüksek değerinin 28 ve 90 günde UK numunelerinde elde edildiği görülmüştür. Referans numunesinin TEBD değerini 28 gün sonunda UK, SD ve Z geçerken; 90 günde ise sadece SD'1 geçmektedir.

Anahtar kelimeler: Bağlayıcı, Puzolanik Aktivite İndeksi, Silis Dumanı, Uçucu Kül, Yüksek Fırın Cürufu, Zeolit

\begin{abstract}
Recently developed and widely used cemented paste backfill (CPB) method; the mining industry has many benefits in terms of the application of the sectoral, operational, environmental and legal legislation on the disposal of mine tailings. That's why; in some mining in our country, cemented paste backfill (CPB) method has been preferred in recent years. One of the biggest cost items of this method is binder expenses. In this study; The use of materials such as zeolite (Z), blast furnace slag (BFS), fly ash (FA), silica fume (SF) instead of Portland cement (PC) used in CPB was examined as pozzolanic additive. The uniaxial compressive strength and flexural strength of the $R, Z, B F S, F A$ and SF doped mixtures were determined after 28 and 90 days. Using uniaxial compressive, flexural strength and puzzolanic activity index values were determined. Firstly, reference samples formed with tailings, cement (11\% by weight) and water were performed Uniaxial compressive strength (UCS) tests and then, UCS tests of $25 \%$ BFS, $20 \%$ Z, $10 \%$ FA, $5 \%$ SF substituted CPB samples were performed after 28 and 90 days curing time. According to the results obtained; The highest compressive and flexural strengths at 28 and 90 days were obtained in UK samples. The highest value of pozzolanic activity index was obtained in UK samples at 28 and 90 days. The UCS value of the reference sample was exceeded by $U K, S D$ and $Z$ at the end of 28 days; in 90 days, it exceeds only $S D$.
\end{abstract}

Keywords: Binder, Puzzolanic Activity Index, Silica Fume, Fly Ash, Blast Furnace Slag, Zeolite

\footnotetext{
*a Hasan EKER; eker_hasan78@ @otmail.com, Tel: (0456) 233 10 00, orcid.org/0000-0003-2644-4681

${ }^{\mathrm{b}}$ orcid.org/0000-0001-7533-4599 $\quad{ }^{\mathrm{c}}$ orcid.org/0000-0002-1611-1296 $\quad{ }^{\mathrm{d}}$ orcid.org/0000-0002-8128-9840
} 


\section{Giriş}

Son zamanlarda ülkemizdeki özellikle metalik maden işletmenlerinde çimentolu macun dolgu (ÇMD) yöntemi tercih edilmektedir. ÇMD; \% 75 85 pülpte katı oranındaki (PKO) tesis atı̆̆ının $(<20 \mu \mathrm{m}$ malzeme miktarı en az $\% 15$ olan) $\% 3$ 11 bağlayıcı (çimento ve puzolan malzemeler) ve pompalanabilir kıvamda olması için yeterli su (proses suyu, musluk ve göl suyu) ile karışımı olarak tanımlanmaktadır (Kesimal vd., 2003; Erçıkd1 vd., 2013; Y1lmaz vd., 2017; Y1lmaz ve Guresci, 2017; Başçetin vd., 2018a,b). Bu yöntemin en büyük maliyet kalemlerinden biri bağlayıcı giderleridir.

Son yıllarda, çeşitli puzolanik malzemeler ve endüstriyel sektörün yan ürünleri madencilik sektöründeki ÇMD'lerin bağlayıcı malzeme tüketimini azaltmak ve ürün performansını artırmak için kullanılmaktadır. Puzolanlar doğal ve yapay puzolanlar olarak ikiye ayrılmaktadır. Volkanik tüf, volkanik küller, kalsine olmuş killer ve şeyller ve ve pomza gibi doğal puzolanlar; harmanlanmış çimento üretiminde, ÇMD için alternatif ve ekonomik puzolanik malzemeler olarak düşünülebilmektedir (Erçıkdı vd., 2010). Yapay ve doğal puzolanların çimento içerikli karışımlarda (beton, harç vb.) kullanılmasının başlıca nedenleri; i) işlenebilirliği iyileştirmek, ii) poroziteyi, boşluk oranını ve geçirgenliği azaltmak, iii) çimento maliyetini/tüketimini azaltmak, iv) kısa ve uzun dönemde daha dayanıklı ürün elde etmek ve, v) sülfat etkisine karşı direnci arttırmak olarak sıralanabilir (Erdoğan, 2003; Alp vd., 2003; Erçıkd1, 2009). Ayrica; puzolan malzemelere ek olarak, Portland çimentosu (PÇ) yerine, atık tuğlalar (WB) ve granüle mermer artıklarının (MW) kullanımı ÇMD'nin dayanım ve duraylılığı üzerinde pozitif bir etkiye sahip olabilmektedir (Külekçi, 2013; Erçıkd1 vd., 2015).

ÇMD üretiminde PÇ yerine kısmi olarak uçucu kül kullanımı birçok araştırmacı tarafından irdelenmiştir (Weaver ve Luka, 1970; Manca vd., 1983; Yu ve Counter, 1988; Udd ve Annor, 1993; Amaratunga ve Hein, 1997; Benzaazoua vd., 1999; Hassani vd., 2001, 2007; Godbout vd., 2009; Değirmenci, 2005; Değirmenci ve Okucu, 2007). C sınıfı uçucu kül ile oluşturulan ÇMD karışımlarının sadece çimento ile oluşturulan karışımlara göre daha iyi dayanım sonucu verdiği görülmüştür (Hassani vd., 2001, 2007; Benzaazoua vd., 2002; Ramlochan vd., 2004).
Demir imalatının metalik olmayan bir yan ürün olan Yüksek firın cürufu (YFC), esas olarak silikatlardan ve kalsiyum alümino silikatlardan oluşmaktadır. YFC, yüksek fırında demir ile aynı anda erimiş, daha sonra camsı tanecikli parçacıklar oluşturmak için suya hızla daldırılarak suda soğutulmasıyla oluşan bir malzemedir (Bouzoubaa ve Simon, 2005). Yüksek firın cürufunu; bazı çalışmalarda çimento yerine ikame olarak kullanılmıştır (Nantel ve Lecuyer, 1983; Douglas ve Malhotra, 1989; Uusitalo vd., 1993; Benzaazoua vd., 2002; Godbout vd., 2007). Literatürde, YFC içeren macun dolgu karışımlarının diğer bağlayıcılarla hazırlanan karışımlara göre dayanım parametrelerinde daha iyi sonuçlar verdiği anlaşılmaktadır. Ayrıca sülfür açısından zengin atıkların kullanıldığı ÇMD karışımlarında, çimento miktarının belirli kısmı yerine ikame edilen YFC, ÇMD'nin uzun vadeli mekanik performansını iyileştirmektedir (Erçıkd1 vd., 2009; Cihangir vd., 2015). Literatürde yapılan çalışmalar dikkate alındığında; YFC, SD ve UK katk1 malzemeleri çimentolu macun dolgu karışımlarında PÇ yerine kullanılmışıır. $\mathrm{Bu}$ çalışmada ise, yüksek sülfür oranına sahip bir bakır atığı ile hazırlanan ÇMD karışımlarında YFC nin sülfat ataklarını önleme potansiyeli araştırılmış, ayrıca $\mathrm{C}$ tipi UK kullanılan daha önceki çalışmalardan farklı olarak F tipi UK tercih edilmiş ve bir bakır atığı ile hazırlanan ÇMD karışımlarında SD kullanılmıştır. Bunlara ek olarak ÇMD karışımlarında daha önceki çalışmalarda kullanılmayan Zeolit bu çalışmada katk1 malzemesi olarak kullanılmış ve başarılı sonuçlar elde edilmiştir.

$\mathrm{Bu}$ çalışmada; ÇMD'de kullanılan Portland çimento $(\mathrm{PCC})$ yerine işletmelerde atık olarak tabir edilen zeolit (Z), yüksek firın cürufu (YFC), uçucu kül (UK), silis dumanı (SD) gibi malzemelerin puzolanik katk1 malzemesi olarak kullanılabilirliği incelenmiştir. $\mathrm{Bu}$ çalışmada referans (R, sadece çimento içeren) ve $Z$, YFC, UK ve SD katkılı ÇMD karışımlarının 28 ve 90 gün kür süreleri sonunda tek eksenli basınç dayanımları ve eğilme dayanımları incelenmiş ve elde edilen tek eksenli basınç ve eğilme dayanımları değerleri kullanılarak puzolanik aktivite indeksi değerleri belirlenmiştir. Sonraki aşamada; bahsi geçen puzolonik malzemeler çimentolara belirli oranlarda ilave edilerek çimentolu macun dolgu karışımları hazırlanmış ve bu numuneler tek eksenli basınç dayanımı deneyine tabi tutulmuştur. 


\section{Malzeme ve Yöntem}

\subsection{Malzeme}

Akçansa Büyükçekmece çimento fabrikasından temin edilen normal Portland çimentosu (CEM I 42.5), zeolit (Z), yüksek firın cürufu (YFC), uçucu kül (UK), silis dumanı (SD) ve standart rilem kumu yapılan çalışmada kullanılmıştır. Ayrıca puzolan maddelerin karışım içerisindeki etkilerini tam olarak anlayabilmek için saf su kullanılmıştır. Zeolit, Balıkesir Bigadiç’te yer alan Eti Maden Bigadiç İşletme Müdürlüğü pasa sahasından; YFC, Kardemir demir - çelik fabrikasından; UK, Zonguldak - Çatalağzı ÇATES termik santralinden ve SD ise Antalya Eti elektrometalürji işletme tesisinden temin edilmiştir. $Z$ ve YFC laboratuvarda önce merdaneli kırıcıdan (- $4 \mathrm{~mm}$ ) geçirilmiştir. Daha sonra $\mathrm{Z}$ bilyalı değirmen vasıtasıyla 45 dakika ögütme süresinde kuru ögütmeye tabi tutularak 125 mikron altına getirilmiştir. YFC ise bilyalı değirmen vasıtasıyla 180 dakika öğütme süresinde kuru öğütmeye tabi tutularak - 125 mikron altına getirilmiştir. Çalışmada kullanılan UK ve SD ise ince olarak temin edildiğinden kırma ve öğütme işlemine tabi tutulmamıştır. Ayrıca, kullanılan atık Kastamonu Küre'de yer alan bir bakır madeninden temin edilmiştir ve tane boyut dağılımı analizine göre $20 \mu \mathrm{m}$ 'dan daha ince tane oranı \% 24,88 olarak bulunduğundan iri boyutlu bir atık sınıfına girmektedir (Başçetin vd., 2018a). Tablo 1'de atık, çimento, zeolit, yüksek firın cürufu, uçucu kül ve silis dumanının fiziksel, kimyasal özellikleri verilmiştir.

Tablo 1. Çimento, zeolit, yüksek fırın cürufu, uçucu kül ve silis dumanının fiziksel, kimyasal özellikleri (Eker, 2019).

\begin{tabular}{|c|c|c|c|c|c|c|}
\hline Özellikler & Atık & $\begin{array}{c}\text { CEM I } \\
42.5 \text { R }(\%)\end{array}$ & $\begin{array}{c}\text { Zeolit } \\
(\%)\end{array}$ & $\begin{array}{l}\text { Yüksek Fırın Cürufu } \\
\text { (Kardemir) (\%) }\end{array}$ & $\begin{array}{c}\text { Uçucu Kül } \\
\text { (Çatalağg)(F Tipi) (\%) }\end{array}$ & $\begin{array}{c}\text { Silis Dumanı } \\
(\%)\end{array}$ \\
\hline \multicolumn{7}{|c|}{ Kimyasal Bileşim } \\
\hline $\mathrm{SiO}_{2}$ & 12.23 & 19.1 & 64.4 & 41.6 & 54.1 & 79.9 \\
\hline $\mathrm{Al}_{2} \mathrm{O}_{3}$ & 4.1 & 4.7 & 10.9 & 11.2 & 26.1 & 0.8 \\
\hline $\mathrm{Fe}_{2} \mathrm{O}_{3}$ & 54.3 & 3.3 & 1.4 & 0.8 & 6.7 & 0.41 \\
\hline $\mathrm{MgO}$ & 2.3 & 1.3 & 1.3 & 7.1 & 2.7 & 7. \\
\hline $\mathrm{SO}_{3}$ & - & 3.5 & - & 0.2 & 0.7 & - \\
\hline $\mathrm{CaO}$ & 1.8 & 64.1 & 3.6 & 34.6 & 2.0 & 2.5 \\
\hline $\mathrm{Na}_{2} \mathrm{O}$ & 0.03 & 0.3 & 0.2 & 0.3 & 0.8 & - \\
\hline $\mathrm{K}_{2} \mathrm{O}$ & 0.09 & 0.9 & 4.3 & 0.7 & 4.5 & - \\
\hline Serbest $\mathrm{CaO}$ & - & 1.65 & - & - & 0.1 & - \\
\hline Kızdırma Kaybı & 24 & 2.09 & 5.13 & 1.00 & 1.36 & 2.96 \\
\hline $\mathrm{MnO}$ & - & - & - & 1.9 & - & - \\
\hline$S$ & - & - & - & 0.5 & - & - \\
\hline $\mathrm{Fe}$ & - & - & - & 0.45 & - & - \\
\hline $\mathrm{TiO}_{2}$ & - & - & - & 1.3 & - & - \\
\hline $\mathrm{Cr}_{2} \mathrm{O}_{3}$ & - & - & - & - & - & 0.38 \\
\hline \multicolumn{7}{|c|}{ Fiziksel Özellikler } \\
\hline Özgül Ağırlık (-) & 3.6 & 3.1 & 2.3 & 3.0 & 2.0 & 3.2 \\
\hline $\begin{array}{l}\text { Özgül } \\
\left(\mathrm{cm}^{2} / \mathrm{g}\right)\end{array} \quad$ Yüzey & 1801 & 3640 & 6132 & 4428 & 2220 & 20100 \\
\hline \multicolumn{7}{|c|}{ Mineralojik Bileşim } \\
\hline $\mathrm{C}_{3} \mathrm{~S}$ & & 63.4 & & & & \\
\hline $\mathrm{C}_{2} \mathrm{~S}$ & & 6.8 & & & & \\
\hline $\mathrm{C}_{3} \mathrm{~A}$ & & 6.9 & & & & \\
\hline $\mathrm{C}_{4} \mathrm{AF}$ & & 9.9 & & & & \\
\hline LSF & & 1.0 & & & & \\
\hline
\end{tabular}




\subsection{Yöntem}

$\mathrm{Bu}$ çalışmada, puzolanik malzemeler ile hazırlanan karışımlar üzerinde yapılan deneyler sonucunda çimento yerine ikame olarak kullanılabilecek bağlayıcı malzemelerin (Z, YFC, UK ve SD) puzolanik aktivite indeksini belirlenmiştir. ASTM C311 (2017) standardına göre; referans çimento (kütlece \% 75) ve puzolan (\% 25) ile hazırlanan karışımlar ve sadece referans çimento ile hazırlanan karışımlar üzerinde basınç dayanımı yapılarak çimento yerine ikame olarak kullanılacak bağlayıcıların puzolanik özellikleri değerlendirilmiştir. Ancak, yüksek fırın cürufunun Puzolanik aktivite indeksi literatürde ASTM C989 (2018) standardına göre belirlenmektedir. Bu standarda referans alınarak hazırlanan, çimento (kütlece \% 50) ve yüksek firın cürufu (\% 50), karışımlar üzerinde deneyler gerçekleştirilmiştir. Tablo 2'de puzolanik aktivite indeksini belirlemek için kullanılan karışım reçeteleri verilmektedir.

Tablo 2. Puzolanik aktivite indeksi karışım reçeteleri

\begin{tabular}{cccccc}
\hline Standart No & Çimento $(\mathbf{g})$ & Kum $(\mathbf{g})$ & Puzolan $(\mathbf{g})$ & Su $(\mathbf{m l})$ & Türü \\
\hline ASTM C 311 & 500 & 1375 & 0 & 242 & Referans \\
ASTM C311 & 400 & 1375 & 100 & 242 & Zeolit \\
ASTM C311 & 400 & 1375 & 100 & 242 & Silis Duman1 \\
ASTM C989 & 250 & 1375 & 250 & 242 & YFC \\
ASTM C311 & 400 & 1375 & 100 & 242 & UK \\
\hline
\end{tabular}

Puzolanik aktivite, "dayanım aktivite indeksi" olarak adlandırılan bir değerin hesaplanmasıyla elde edilmektedir (Eşitlik 1).

Dayanım aktivite indeksi $=(\mathrm{A} / \mathrm{B}) \times 100$

\section{Burada;}

A: Puzolanlı harç numunelerinin ortalama basınç dayanım1,

B: Kontrol harç numunelerinin ortalama basınç dayanımını ifade etmektedir.

Tablo 2'de verilen karışım oranlarında hazırlanan numuneler için ikişer karışım oluşturulmuştur. Karışımların her birinin; 40 × 40 x $160 \mathrm{~mm}$ ölçülerindeki üç gözlü kalıplara dökümü gerçekleştirilmiştir. Daha sonrasında en az $20^{\circ} \mathrm{C}$ ve $\% 80$ nemli bir ortamda 24 saat bekleme süresinin ardından kalıplardan çıkarılan numuneler kür havuzunda belirlenen kür sürelerine (28 ve 90 gün) kadar bekletilmiştir.

Kür süreleri sonunda her bir kür süresi için 3 adet numune kullanılarak eğilme dayanımı deneyleri gerçekleştirilmiştir. Basınç dayanımı için ise 6 adet numune kullanılmıştır. Eğilme dayanımı deneyleri ve basınç dayanımı deneyleri; TS EN 196 - 1 standardına uygun olarak Şekil 1'de gösterilen 200 tonluk ve $50 \mathrm{~N} / \mathrm{s}$ yükleme hızına sahip beton presi ile gerçekleştirilmiştir. Puzolanik aktivite dayanım indeksini belirlemek için eğilme dayanımında kullanılan numunelerin kırılan parçaları kullanılarak basınç dayanımını yapılmıştır.

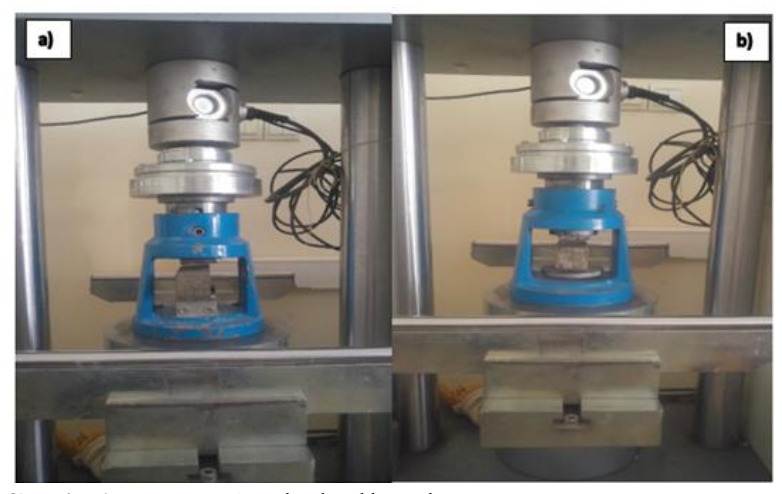

Şekil 1. Deneylerde kullanılan pres

Puzolanik aktivite indeksi deneylerinden sonra Çimentolu macun dolgu (ÇMD) deneyleri yapılmıştır. Atığın (ağırlıkça \% 11 oranlarında), çimento ve şebeke suyu ile karıştırılmasıyla referans numuneleri ve daha sonra kullanilan çimento miktarının \% 25 oranında yüksek firın cürufu (YFC), \% 20 oranında zeolit (Z), \% 10 oranında uçucu kül (UK) ve \% 5 oranında silis dumanı (SD) ikameli içeren çimentolu macun dolgu numuneleri oluşturulmuştur. Atıkların alındığı işletmede ağırlıkça \% 11 çimento oranı tercih edildiği için çalışmamızda bu oran tercih edilmiştir. Tablo 3'te çimentolu macun dolgu karışımlarının reçeteleri verilmiştir. Karışım oranları belirlenirken daha önce yapılan ön deney sonuçları kullanılmıştır. Ön deney sonuçlarına göre en iyi dayanıma sahip karışımlar bu çalışma için seçilmiştir. Homojen bir yapıda olması için hazırlanan macun dolgu karışımları bir mikser vasitasıyla ve yapılan ön deneyler sonucu elde edilen karıştırma süresine göre $10 \mathrm{dk}$ 
karıştırılmıştır. Ayrıca bu macun dolgu karışımları $18 \mathrm{~cm}$ çökme (slump) değerine ve \%81 katı oranına göre hazırlanmıştır. ÇMD uygulamalarında, slump değeri 15.2-25.4 cm arasındadır ve en çok tercih edilen slump değeri 18 olması nedeniyle bu değer kullanılmıştır (Fall vd., 2009). Macun dolgu karışımları $5 \mathrm{~cm}$ çapında ve $10 \mathrm{~cm}$ yüksekliğindeki drenajlı (alt kısmında 4 adet delik bulunan) silindirik numune kalıplarına dökülmüş ve en az $\% 80$ nem oranında ve $25^{\circ} \mathrm{C}$ sicaklığa ayarlanan kür kabininde belirlenen kür sürelerinde (28 ve 90 gün) bekletilmiştir. Belirlenen kür süreleri sonunda TEBD deneyleri silindirik numuneler üzerinde ASTM C 39 (2018) standardına uygun olarak $50 \mathrm{kN}$ yükleme kapasitesine sahip $0.5 \mathrm{~mm} / \mathrm{dk}$ sabit yükleme hızında otomatik kontrollü preste yapılmıştır.

Tablo 3. Çimentolu macun dolgu karışımlarının reçeteleri

\begin{tabular}{|c|c|c|c|c|c|}
\hline \multirow{2}{*}{ Numune Ad1 } & \multicolumn{2}{|c|}{ İkame Oranı (Ağr. \%) } & \multirow{2}{*}{$\begin{array}{l}\text { Katı Oranı } \\
\text { (Ağr. \%) }\end{array}$} & \multirow{2}{*}{$\begin{array}{l}\text { Slump } \\
\text { (Çökme)(cm) }\end{array}$} & \multirow{2}{*}{$\begin{array}{l}\text { Bağlayıcı } \\
\text { Oranı (Ağr } \\
\%)\end{array}$} \\
\hline & $\begin{array}{l}\text { Portland } \\
\text { Çimento }\end{array}$ & $\begin{array}{l}\text { Puzolan } \\
\text { Malzemeler }\end{array}$ & & & \\
\hline Referans & 100 & - & \multirow{5}{*}{81} & \multirow{5}{*}{18} & \multirow{5}{*}{11} \\
\hline Zeolit (Z) & 80 & 20 & & & \\
\hline Uçucu Kül (UK) & 90 & 10 & & & \\
\hline Yüksek Furın Cürufu (YFC) & 75 & 25 & & & \\
\hline Silis Dumanı (SD) & 95 & 5 & & & \\
\hline
\end{tabular}

\section{Bulgular ve Tartışma}

TS 25 standardına göre Z'in puzolanik özellikleri değerlendirildiğinde; $\mathrm{SiO}_{2}+\mathrm{Al}_{2} \mathrm{O}_{3}+\mathrm{Fe}_{2} \mathrm{O}_{3}$ toplamının en az \% 70, kızdırma kaybı değerinin en fazla \% 10, $\mathrm{MgO}$ değerinin $\% 5$ 'ten küçük, $\mathrm{SO}_{3}$ değerinin ise en fazla 3 ve özgül yüzey alanının $3000 \mathrm{~cm}^{2} / \mathrm{g}$ 'dan büyük olmas1 gerekmektedir. Buna göre; $\mathrm{SiO}_{2}+\mathrm{Al}_{2} \mathrm{O}_{3}+\mathrm{Fe}_{2} \mathrm{O}_{3}$ toplamının \% 76.7, kızdırma kaybı değerinin \% 5.1, $\mathrm{MgO}$ değerinin \% 1.3, $\mathrm{SO}_{3}$ değerinin saptanamadığ 1 ve özgül yüzey alanının $6132 \mathrm{~cm}^{2} / g$ olduğu ve sınır değerleri sağladığı görülmektedir.

TS EN 450 standardına göre UK'ün puzolanik özellikleri incelendiğinde; $\mathrm{SiO}_{2}+\mathrm{Al}_{2} \mathrm{O}_{3}+\mathrm{Fe}_{2} \mathrm{O}_{3}$ toplamının en az \% 70, kızdırma kaybı değerinin en fazla $\% 5, \mathrm{SO}_{3}$ değerinin ise en fazla 3 olmas1 gerekmektedir. ASTM C 618 (2019) standardına göre ise; $\mathrm{SiO}_{2}+\mathrm{Al}_{2} \mathrm{O}_{3}+\mathrm{Fe}_{2} \mathrm{O}_{3}$ toplamının en az $\% 70$, kızdırma kaybı değerinin en fazla $\% 6, \mathrm{SO}_{3}$ değerinin ise en fazla 5 olması gerekmektedir. Buna göre UK'ün $\mathrm{SiO}_{2}+\mathrm{Al}_{2} \mathrm{O}_{3}+\mathrm{Fe}_{2} \mathrm{O}_{3}$ toplamının \% 87.7, kızdırma kaybı değerinin \% $1.4, \mathrm{SO}_{3}$ değerinin ise \% 0.7 olduğu ve sinır değerleri sağladığ 1 görülmektedir. YFC'unun puzolanik özellikleri ASTM C 618 (2019)'ye göre incelendiğinde; $\mathrm{SiO}_{2}+\mathrm{Al}_{2} \mathrm{O}_{3}+\mathrm{Fe}_{2} \mathrm{O}_{3}$ toplamının $\%$ 53.6, kızdırma kaybı değerinin \% 1.0, $\mathrm{SO}_{3}$ değerinin ise \% 0.2 olduğu ve sinır değerleri sağladığı görülmektedir. SD'ının puzolanik özellikleri ASTM C 618 (2019)'ye göre incelendiğinde; $\mathrm{SiO}_{2}+\mathrm{Al}_{2} \mathrm{O}_{3}+\mathrm{Fe}_{2} \mathrm{O}_{3}$ toplamının
$\%$ 81.2, kızdırma kaybı değerinin \% 3.0, $\mathrm{SO}_{3}$ değerinin saptanamadığ sağladığı görülmektedir.

\subsection{Puzolanik Aktivite Deneyleri}

\subsubsection{Basınç Dayanımı}

Çalışma kapsamında çimento yerine ikame olarak kullanılan puzolanik malzemeler (Z, YFC, UK ve SD) ve referans karışım kullanılarak Tablo 2'de belirtilen reçeteye göre hazırlanan numunelerin, 28 ve 90 gün kürlenmesi sonunda yapılan basınç dayanımı deneyi sonuçları Şekil 2'de verilmiştir.

Şekil 2'de görüldüğü üzere kür süresine bağlı olarak Z, YFC, UK ve SD içeren numunelerin basınç dayanımlarının arttığı görülmektedir. Referans numunesine göre 28. günde bütün numunelerin (Z, YFC, UK ve SD) dayanımının düşük olduğu, 90. günde ise $Z$ ve UK'ün referans numunesine göre daha yüksek dayanım değeri aldığı görülmektedir. $Z$ ve UK'ün karışımlarına eklenmesi sonucu referans numunelerinde yer alan boşlukların azalmasıyla bu yükseliş gerçekleşmiştir (Fall vd., 2005; Erçıkd1 vd., 2013; Y1lmaz vd., 2017; Eker, 2019). SD ve YFC'nun ise referansa göre 90 . günde de düşük dayanım elde ettiği görülmektedir. 28 gündeki R, Z, UK, SD ve YFC'u numunelerinin 90 gün sonundaki basınç dayanım değerlerine göre sırasıyla \% 7.7 düşüş, \% 13.5 artış, $\% 20$ artış, $\% 15$ artış ve $\%$ 2.2 artış meydana gelmiştir. 


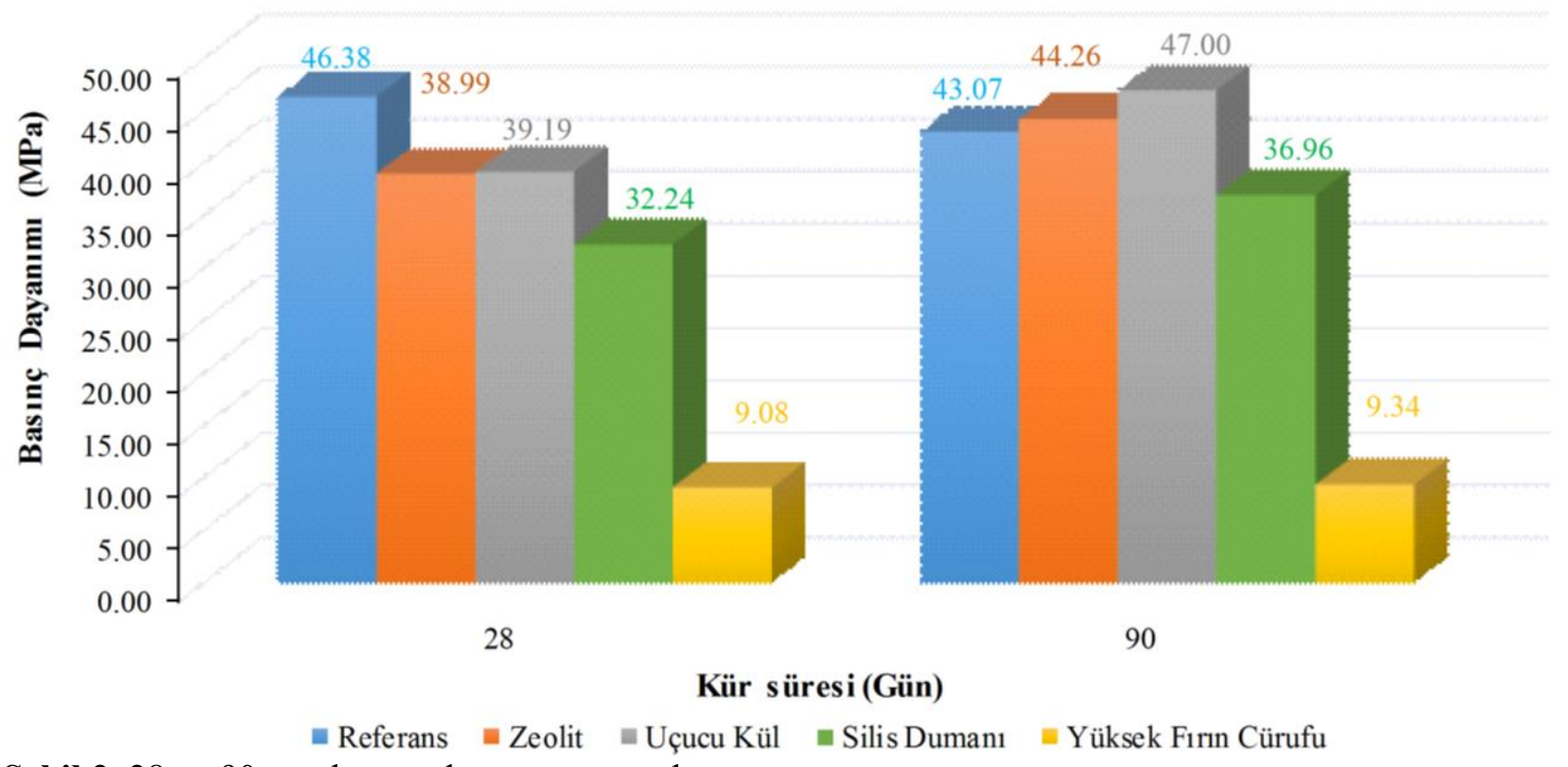

Şekil 2. 28 ve 90 gün basınç dayanımı sonuçları

\subsection{2. Ĕ̈ilme Dayanımı}

Çalışma kapsamında çimento yerine ikame olarak kullanılan puzolanik malzemeler (Z, YFC, UK ve
SD) ve referans karışım kullanılarak Tablo 2'de belirtilen reçeteye göre hazırlanan numunelerin, 28 ve 90 gün kürlenmesi sonunda yapılan eğilme dayanım sonuçları Şekil 3’te verilmiştir.

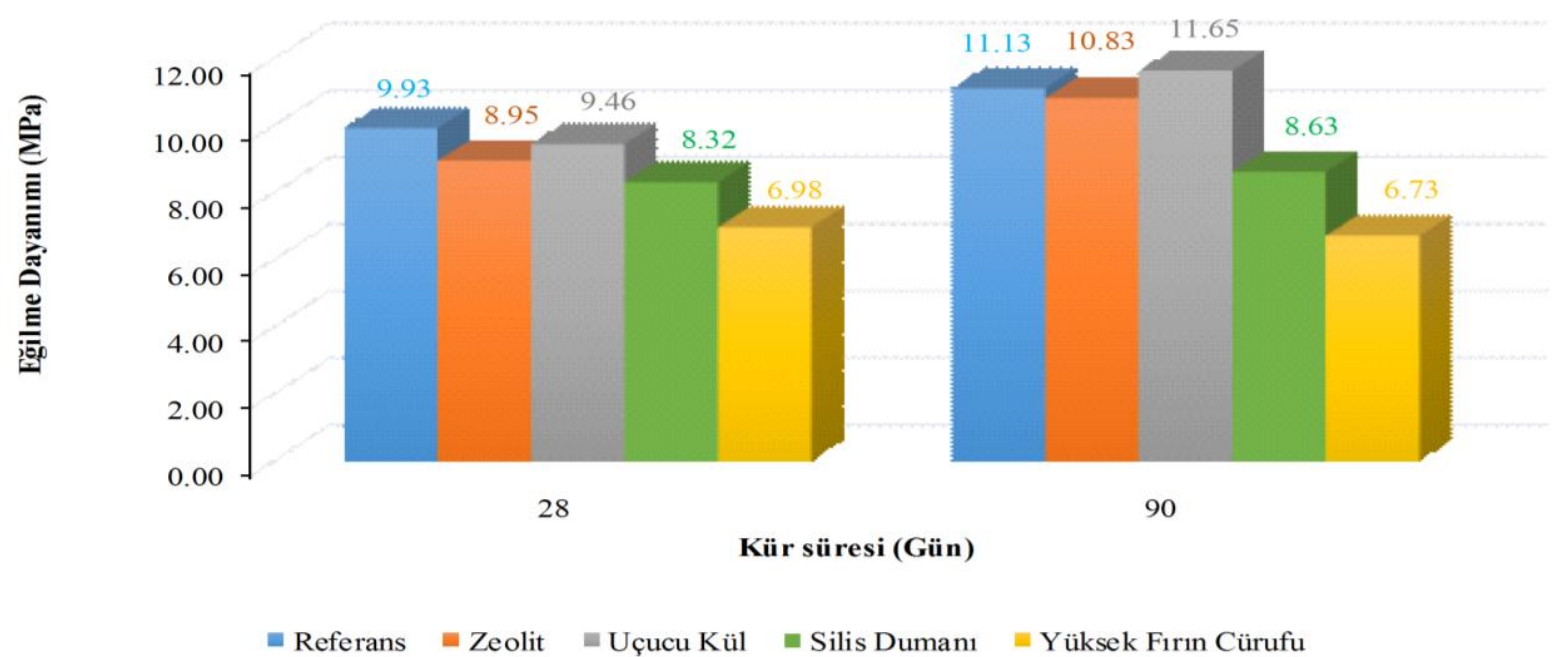

Şekil 3. 28 ve 90 günlük numunelerin eğilme dayanımı sonuçları

Şekil 3'te görüldüğü gibi 28 ve 90 günlük kür sürelerine bağlı olarak YFC hariç $Z$, UK ve $S D$ içeren numunelerin eğilme dayanımlarının arttı̆g 1 görülmektedir. Referans numunesine göre 28. günde bütün numunelerin (Z, YFC, UK ve $S D)$ dayanımının düşük olduğu, 90 . günde ise sadece UK'ün referans numunesine göre daha yüksek dayanım değeri aldığı görülmektedir. Puzolanik malzemelerin dayanım üzerindeki olumlu etkileri uzun dönemde ortaya çıkmıştır. 8 gündeki R, Z, $\mathrm{UK}$, SD ve YFC'u numunelerinin 90 gün sonundaki eğilme dayanımı değerlerine göre sirasıyla \% 12.1 artış, \% 20 artış, \% 23.2 artış, \% 3.6 artış ve $\% 4.5$ düşüş meydana gelmiştir.

\subsubsection{Puzolanik Aktivite Índeksi}

Çalışma kapsamında çimento yerine ikame olarak kullanılan puzolanik malzemeler (Z, YFC, UK ve SD) ve referans karışım kullanılarak hazırlanan numunelerin, 28 ve 90 gün kürlenmesi sonunda Eşitlik 1 ve basınç dayanımı deney sonuçları kullanılarak hesaplanan puzolanik aktivite indeksi değerleri Şekil 4'te verilmiştir. 


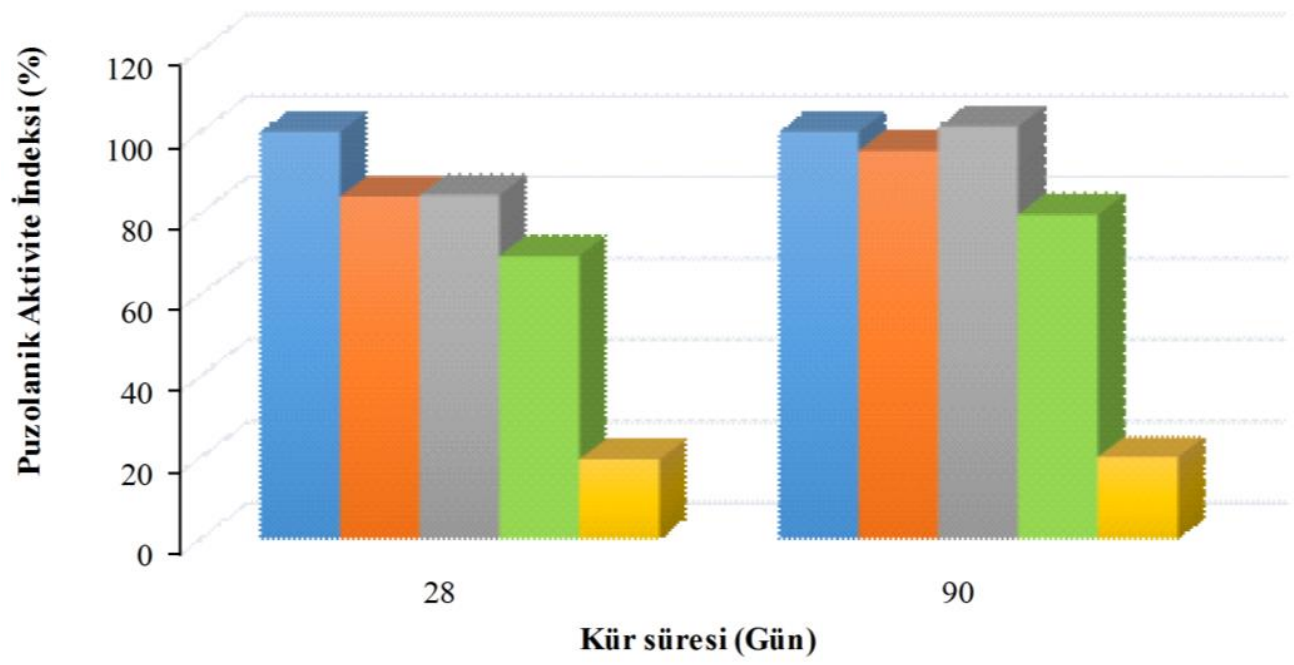

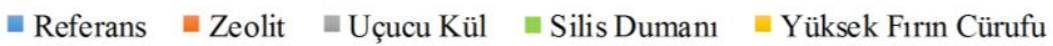

Şekil 4. Puzolanik aktivite indeksi sonuçları

Şekil 4'te görüldüğü gibi Z, UK, SD ve YFC katk1 malzemeleri ile hazırlanan karışımların puzolanik aktivite indeksi değerleri sırasıla; 28 . günde $\%$ $84.1, \% 84.5, \% 69.5$ ve $\% 19.6 ; 90$. günde ise $\%$ 95.4, \% $101.3, \quad \% \quad 79.7$ ve \% 20.2 olarak hesaplanmıştır. Buna göre $Z$, UK ve SD standartlarda belirtilen bu koşulları sağlamaktadır. Ancak YFC puzolanik aktivite sınır değerini sağlamamaktadır. 28 günlük kür süresi sonunda YFC, UK ve SD puzolanik aktivite indeksi sırasıyla $\% 74, \% 80.5$ ve $\% 124$ elde edilmiştir (Erçıkd1, 2009). UK değeri hariç diğer iki puzolan malzemenin Erçıkdı (2009) çalışmasında elde edilen sonuçların altında kaldığı görülmektedir.

\section{2. Çimentolu Macun Dolgu Numunelerinin Tek Eksenli Basınç Dayanımı}

Atık, çimento (ağırlıç̧a \% 11 ) ve su ile oluşturulan referans numuneleri ve çimentonun yerine (\% 11) \% 25 oranında YFC, \% 20 Z, \% 10 UK, $\% 5$ SD ikameli ÇMD numunelerinin 28 ve 90 günlük kür süreleri sonunda yapılan tek eksenli basınç dayanımı (TEBD) sonuçları Şekil 5'te verilmiştir.

ÇMD numunelerinin yeraltı boşluklarında ara katlı dolgu için 28 günde en az $1 \mathrm{MPa}$, serbest durma ya da tavanı tutma özelliği için ise en az 4 $\mathrm{MPa}$ dayanımı sağlaması beklenmektedir (Fall vd., 2005; Cihangir vd., 2012; Başçetin 2018a,b).

28 gün sonunda $\mathrm{YFC}, \mathrm{R}, \mathrm{UK}, \mathrm{Z}, \mathrm{SD}$ 'in TEBD sonuçları sırasıyla; 3.4, 4.9, 5.0, 6.1, 8.1 MPa'dır. 90 günde YFC, UK, Z, R, SD'ının TEBD sonuçları sırasıyla; ise $2.1,3.3,3.6,5.6$ ve 7.8
MPa'dır. Referans numunesinin TEBD değerini 28 gün sonunda UK, SD ve $Z$ geçerken; 90 günde ise sadece SD'1 geçmektedir (Şekil 5). Puzolanik aktivite indeksi değerleri yüksek olan katkıların TEBD değerlerinin de yüksek çıktığı görülmüştür. Kür süresine bağlı olarak TEBD değerlerinde meydana gelen bu düşüş atığın bünyesinde bulunan kükürt miktarının fazla olmasından kaynaklanmaktadır (Benzaazoua vd., 1999; Hassani vd., 2001; Tariq ve Nehdi, 2007; Belem ve Benzaazoua, 2008; Erçı1kd1 vd., 2009, 2009b; Cihangir vd., 2011, 2012). 90 gün sonunda çimento yerine ikame edilen bağlayıcılar arasından en fazla dayanımı veren ve en az dayanım kaybına sahip silis dumanı numunesidir. Ayrıca puzolanik aktivite indeksi sınır değerlerini sağlayan $\mathrm{SD}, \mathrm{Z}$ ve UK'ün TEBD değerleri de yüksek çıkmıştır.

ÇMD karışımlarında (sülfür açısından zengin atık içeren), çimento miktarının belirli kısmı yerine ikame edilen YFC, ÇMD'nin uzun vadeli mekanik performansını iyileştirdiği önceki çalışmalarda (Erçıkdı vd. 2009; Cihangir vd. 2015) belirtilse de Şekil 5'te görüldüğü üzere 90 günlük kür süresi sonunda dayanımda düşüş meydana gelmiştir. Ayrıca UK ikameli karışımında C tipi UK içeren çalışmaların (Hassani vd., 2001, 2007; Benzaazoua vd., 2002; Ramlochan vd., 2004; Erçıkd1, 2009) aksine referans değerinin basınç dayanımını altında olduğu görülmüştür. SD ikameli ÇMD numunelerinin ise referans numunesinin basınç dayanımın değerini (Erçıkdı vd., 2009) çalışmasında olduğu gibi geçtiği görülmektedir. 


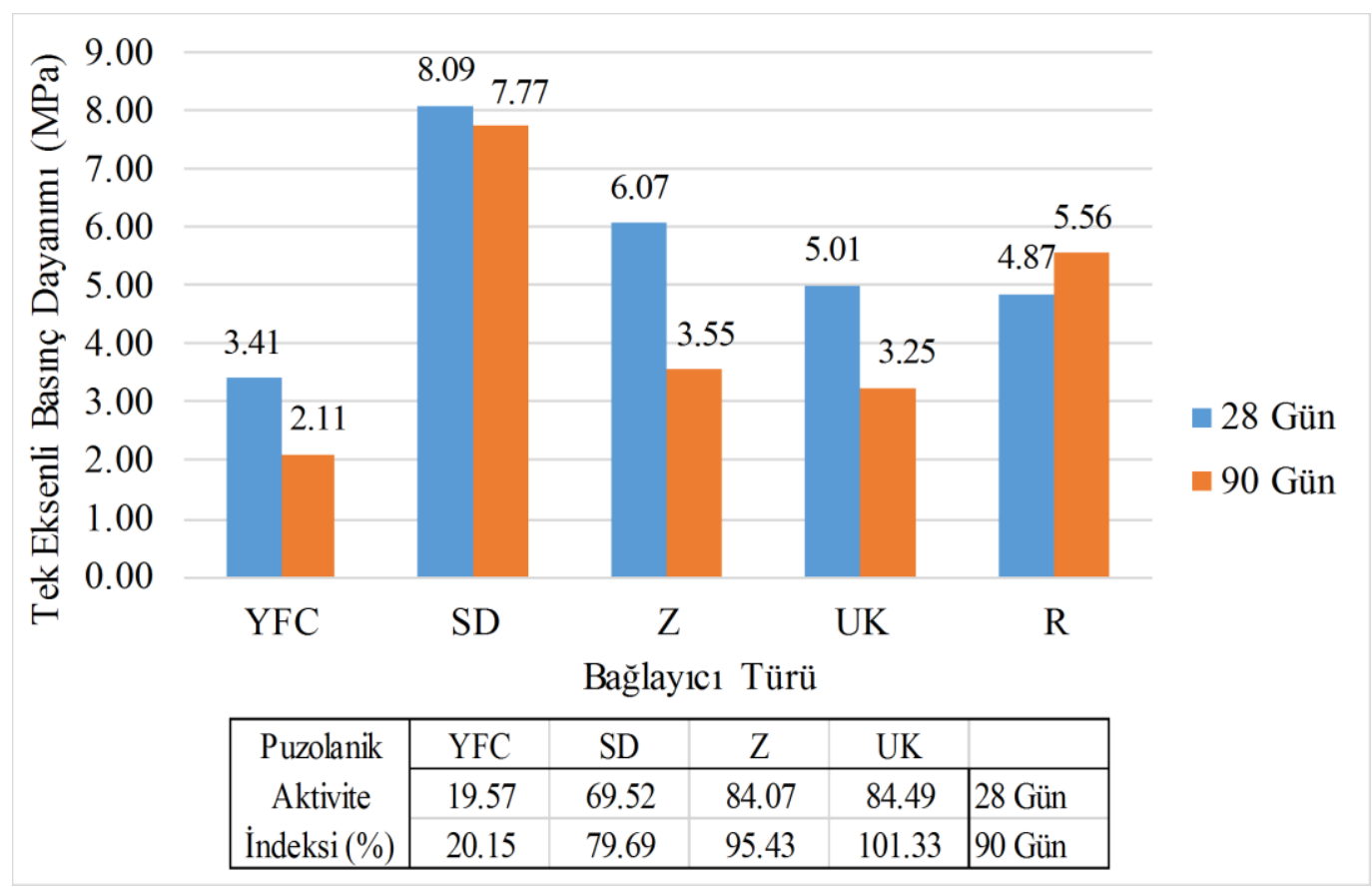

Şekil 5. Tek eksenli basınç dayanımı sonuçları

\section{Sonuçlar}

Bu çalışmada; ÇMD'da çimento maliyetlerinin azaltılması için çimento yerine ikame olarak kullanılan endüstriyel atıklardan zeolit, yüksek fırın cürufu, uçucu kül ve silis dumanı gibi malzemelerin puzolanik katk1 malzemesi olarak kullanılabilirliği incelenmiştir. $\mathrm{Bu}$ kapsamda hazırlanan referans, zeolit, yüksek firın cürufu, uçucu kül ve silis dumanı katkılı karıșımların 28 ve 90 gün kür süreleri sonunda basınç dayanımı ve eğilme dayanımları belirlenmiş ve bulunan sonuçlar ile malzemelerin puzolanik aktivite indeksi değerleri elde edilmiştir. Ayrıca belirli oranlarda çimento yerine ikame edilen Z, YFC, UK ve SD ile oluşturulan ÇMD karışımlarının 28 ve 90 gün sonundaki TEBD sonuçları da puzolanik aktivite indeksi sonuçları ile beraber değerlendirilmiştir.

Elde edilen sonuçlara göre; 90 günlük kür süresi sonunda referans numunesinin basınç dayanımı değerini; $Z$ ve UK numuneleri geçmektedir. Ayrıca sadece UK numunesinin eğilme dayanım değerinin, referansın dayanım değerinin üzerinde olduğu görülmüştür. Bununla birlikte; zeolit; uçucu kül ve silis dumanı ile hazırlanan numunelerin puzolanik aktivite indeksi değerleri yüksek çıkmıştır. Ayrıca çimento yerine ikame edilen bu bağlayıcılar ÇMD numunelerinde dayanımı olumlu yönde geliştirerek dayanım artışını sağlamışlardır. $\mathrm{Bu}$ sonuç; ÇMD'de kullanılacak çimentonun miktarını ve maliyetini azaltmak için malzemelerin çimento yerine ikame olarak kullanılabileceğini ortaya koymuştur. Böylece çimento üretimi sırasında sera gazı etkisi oluşturan $\mathrm{CO}_{2}$ salınım miktarını da azaltma imkanı oluşmuştur. Buna ilaveten işletmelerde atık olarak nitelendirilen bu malzemelerin yeniden kullanımı sağlanarak işletmeye, ekonomik bir gelir sağlayacaktır. Çalışma ile ortaya çıkan sonuçlar ile madencilik atıklarında puzolan katkıların kullanılması ile sektörümüz için işletme, çevre ve maliyet açısından önemli faydalar sağlanabileceği görülmektedir.

\section{Teşekkür}

$\mathrm{Bu}$ çalışma İstanbul Üniversitesi Bilimsel Araştırma Projeleri Koordinasyon Birimi tarafindan desteklenmiştir. Proje numarası: FDK2018-24707.

\section{Kaynaklar}

Alp, I., Deveci, H., Yılmaz, E., Yılmaz, A.O. ve Kesimal, A., 2003. Investigation of The Potential Use of the Quarry Product from Tas, Hane-Terme As Trass Raw Material in Cement Industry, in: E. Yüzer, H. Ergin, A. Tuğrul (Eds.), Proceedings of the International Symposium on Industrial Minerals and Building Stones, Istanbul, Turkey, pp. 553-559.

Amaratunga, L.M. ve Hein, G.G., 1997. Development of a High Strength Total Tailings Paste Fill Using Fine Sulphide Mill Tailings, In: Proceedings of the 29th Annual Conference of the Canadian Mineral Processor (CIMCMP), pp. 293-305. 
ASTM C39 / C39M-18, 2018. Standard Test Method for Compressive Strength of Cylindrical Concrete Specimens, ASTM International, West Conshohocken, PA, www.astm.org.

ASTM C 311, 2017. Standard Test Methods for Sampling and Testing Fly Ash or Natural Pozzolans for Use in Portland-Cement Concrete, ASTM International, West Conshohocken, PA.

ASTM C618-19, 2019. Standard specification for coal fly ash and raw or calcined natural pozzolan for use in concrete, ASTM International, West Conshohocken, PA, www.astm.org.

ASTM C 989 / C989M-18a, 2018. Standard Specification for Slag Cement for Use in Concrete And Mortars, ASTM International, West Conshohocken, PA, www.astm.org.

Başçetin, A., Eker, H., Tüylü, S. ve Adigüzel, D., 2018a. Bir Bakır Madeni Artıklarının Dayanım Özelliklerinin Belirlenmesi, KAYAMEK'201812. Bölgesel Kaya Mekaniği Sempozyumu, 3-5 Ekim 2018, Trabzon, Türkiye, 162-167.

Başçetin, A., Eker, H., Tüylü, S. ve Adıgüzel, D., 2018b. Zeolit İkamesinin Çimentolu Macun Dolgunun Mekanik Özelliklerine Etkisi, Proceedings of the 4 th International Underground Excavations Symposium, UYAK 2018, İstanbul, s. 575-581.

Belem, T. ve Benzaazoua, M., 2008. Design and Application of Underground Mine Paste Backfill Technology, Geotechnical and Geological Engineering, 26, 147-174.

Benzaazoua, M., Ouellet, J., Servant, S., Newman, P. ve Verburg, R., 1999. Cementitious Backfill with High Sulphur Content: Physical, Chemical And Mineralogical Characterization. Cem. Concr. Res. 29(5), 719 - 725.

Benzaazoua, M., Belem, T. ve Bussiere, B., 2002. Chemical Factors that Influence the Performance of Mine Sulphidic Paste Backfill, Cement and Concrete Research, 32(7), 1133 1144.

Bouzoubaa, N. ve Simon, F.S., 2005. Use of Fly Ash and Slag in Concrete: a Best Practice Guide. Materials Technology Laboratory (MTL), Public Works and Government Services, Government of Canada, 2004 - 16.

Cihangir, F., Ercıkdı, B., Turan, A., Kesimal, A., Deveci, H., Yazıcı, M. ve Karaoğlu, K., 2011. Utilisation of Sodium Silicate Activated Blast Furnace Slag as an Alternative Binder in Paste Backfill of High-Sulphide Mill Tailings, In: Proceedings of the 14th International Seminar on Paste and Thickened Tailings, Perth, Australia, p 465-475.

Cihangir, F., Erçıkdı, B., Kesimal, A., Turan A. ve Deveci, H., 2012. Utilisation of AlkaliActivated Blast Furnace Slag in Paste Backfill of High-Sulphidemill Tailings: Effect of Binder Type and Dosage, Minerals Engineering, 30, 33-43.

Cihangir, F., Erçıkdı, B., Kesimal, A., Deveci, H. ve Erdemir, F., 2015. Paste Backfill of HighSulphide Mill Tailings Using Alkaliactivated Blast Furnace Slag: Effect of Activator Nature, Concentration And Slag Properties, Minerals Engineering, 83, 117-127.

Değirmenci, N., 2005. The Use of Industrial Wastes in Adobe Stabilization, G.Ü. Fen Bilimleri Dergisi, 18(3), 505-515.

Değirmenci, N. ve Okucu, A., 2007. Usability of Fly Ash and Phosphogypsum in Manufacturing of Building Products, Pamukkale Üniversitesi Mühendislik Fakültesi, Mühendislik Bilimleri Dergisi, 2(2), 273-278.

Douglas, E. ve Malhotra, V.M., 1989. Ground Granulated Blast-Furnace Slag for Cemented Mine Backfill: Production and Evaluation, CIM Bull. 82, 929, 27-36.

Eker, H. 2019, Metalik Proses Artıklarının Macun Dolgu Yöntemi ile Depolanmasında Uygun Tasarım Parametrelerinin Belirlenmesi, İstanbul Üniversitesi-Cerrahpaşa, Lisansüstü Eğitim Enstitüsü, İstanbul.

Erçıkd1, B. 2009. Mineral ve Kimyasal Katk1 Maddelerinin Macun Dolgu Performansina Etkisi, Karadeniz Teknik Üniversitesi, Fen Bilimleri Enstitüsü, Trabzon.

Erçıkdı, B., Cihangir, F., Kesimal, A., Deveci, H. ve Alp, I., 2009. Utilization of Industrial Waste Products as Pozzolanic Material in Cemented Paste Backfill of High Sulphide Mill Tailings, Journal of Hazardous Materials, 168, 848-856.

Erçıkdı, B., Kesimal, A., Cihangir, F., Deveci, H. ve Alp, I., 2009b. Cemented Paste Backfill of Sulphide-Rich Tailings: Importance of Binder Type and Dosage. Cement and Concrete Composites, 31, 268-274.

Erçıkdı, B., Cihangir, F., Kesimal, A., Deveci, H. ve Alp, I., 2010. Effect of Natural Pozzolans as Mineral Admixture on the Performance of Cemented-Paste Backfill of Sulphide-Rich Tailings, Waste Management and Research, 28, 430-435.

Erçıkdı, B., Baki, H. ve İzki, M., 2013. Effect of Desliming of Sulphide-Rich Mill Tailings on 
the Long-Term Strength of Cemented Paste Backfill, Journal of Environmental Management 115,5-13.

Erçıkdı, B., Külekci, G. ve Yılmaz, T., 2015. Utilization of Granulated Marble Wastes and Waste Bricks as Mineral Admixture in Cemented Paste Backfill of Sulphide-Rich Tailings, Construction and Building Materials 93, 573-583.

Erdoğan, T.Y., 2003. Beton, ODTÜ Geliştirme Vakfı Yayıncılık ve İletişim A.Ş. Yayını, Ankara.

Fall, M., Benzaazoua, M. ve Ouellet, S., 2005. Experimental Characterization of The Influence of Tailings Fineness and Density on the Quality of Cemented Paste Backfill, Minerals Engineering, 18(1), 41-44.

Fall, M., Adrien, D., Celestin, J.C., Pokharel, M. ve Touré, M., 2009. Saturated Hydraulic Conductivity of Cemented Paste Backfill. Minerals Engineering, 22(15), 1307-1317.

Godbout, J., Bussière, B., Aubertin, M. ve Belem, T., 2007. Evolution of Cemented Past Backfill Saturated Hydraulic Conductivity at Early Curing Time, In: Diamond Jubilee Canadian Geotechnical Conference and the 8th Joint CGS/IAH-CNC Groundwater Conference, Ottawa, Ontario. Canadian Geotechnical Society, Alliston, Ontario.

Hassani, F.P., Ouellet, J. ve Hossein, M., 2001. Strength development in underground high sulphate paste backfill operation, CIM Bull. 94 (1050), 57 - 62.

Hassani, F.P., Nokken, M.R., Annor, A.B., 2007. Physical and Mechanical Behaviour of Various Combinations of Mine Fill Materials, CIM Bull. $2(3), 72$.

Kesimal, A., Erçikdi, B. ve Yilmaz, E., 2003. The Effect of Desliming by Sedimentation on Paste Backfill Performance, Minerals Engineering 16(10), 1009-1011.

Külekçi, G., 2013. Investigation of the Utility of the Waste Brick And Marble on the Paste Backfill (M.Sc. thesis), Karadeniz Technical University, $72 \mathrm{p}$.

Manca, P.P., Massacci, G., Massidda, L. ve Rossi, G., 1983. Mill Tailings and Various Binder Mixtures for Cemented Backfill: Analysis of Properties Related to Mining Problems. in: Proceedings 3rd International Symposium on Mining with Backfill, pp. 39 - 47.
Nantel, J. ve Lecuyer, N., 1983. Assessment of Slag Backfill Properties for the Noranda Chadbourne Project, CIM Bull. 849, 57 - 60.

Ramlochan, T., Thomas, M., ve Hooton, R. 2004. The Effect of Pozzolans and Slag on the Expansion of Mortars Cured at Elevated Temperature: Part II: Microstructural and Microchemical Investigations, Cement and Concrete Research, 34(8), 1341-1356.

Tariq, A., Nehdi, M., 2007. Developing Durable Paste Backfill from Sulphidic Tailings, Waste Res Manage, 160(4), 155-166.

TS 25, 2015. Doğal Puzolan (Tras)-Çimento ve Betonda Kullanılan-Tarifler, Gerekler ve Uygunluk Kriterleri, Türk Standartları Enstitüsü.

TS EN 196-1, 2016. Çimento Deney Metotları - Bölüm 1: Dayanım Tayini, Türk Standartları Enstitüsü.

TS EN 450-1, 2013. Uçucu Kül - Betonda Kullanılan Bölüm 1: Tarif, Özellikler ve Uygunluk Kriterleri, Türk Standardı, 2013.

Udd, J.E. ve Annor, A., 1993. Backfill Research in Canada. In: Proceedings, Fifth International Symposium on Mining with Backfill, The South African Institute of Mining and Metallurgy, pp. 361-368.

Uusitalo, R., Seppanen, P. ve Nieminin, P., 1993. The Use of Blast Furnace Slag as a Binder, In: Symposium Presented at the Fifth International Symposium on Mining with Backfill, pp. 169172. Johannesburg, South Africa.

Weaver, W.S. ve Luka, R., 1970. Laboratory Studies of Cemented-Stabilized Mine Tailings, CIM Bull. 701, 988-1001.

Yılmaz, T., Erçıkdı, B. ve Cihangir, F., 2017. Yüksek Fırın Cürufu ve Perlit İkamesinin Çimentolu Macun Dolgunun Mekanik ve Mikroyap1 Özelliklerine Etkisi, Çukurova Üniversitesi Mühendislik Mimarlık Fakültesi Dergisi, 32(2), 239-251.

Y1lmaz, E. ve Guresci, M. 2017. Design and Characterization of Underground Paste Backfill, in: Paste Tailings Management, Yilmaz E, Mamadou, F, Eds, Springer, London/Berlin/Switzerland, Cham, pp,111-144.

Yu, T.R. ve Counter, D.B., 1988. Use of Fly Ash in Backfill at Kidd Creek Mines; CIM Bull. 81, 909, 44-50. 